\title{
Efficacy and safety of a crystalline lactulose preparation (SK-1202) in Japanese patients with chronic constipation: a randomized, double-blind, placebo-controlled, dose-finding study
}

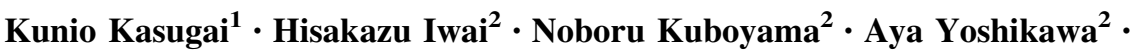 \\ Shin Fukudo ${ }^{3}$
}

Received: 25 June 2018/Accepted: 27 December 2018/Published online: 14 January 2019

(C) The Author(s) 2019

\begin{abstract}
Background Clinical evidence of lactulose for chronic constipation in Japan was lacking. We performed a randomized, double-blind, placebo-controlled, dose-finding study in Japanese patients with chronic constipation to estimate the optimal clinical dose of lactulose.

Methods Overall, 250 patients were randomized to receive SK-1202 (13, 26, or $39 \mathrm{~g} /$ day, as crystalline lactulose dosage) or placebo twice daily (morning and evening) orally for 2 weeks. The primary endpoint was the change from baseline frequency of spontaneous bowel movements (SBMs) at Week 1. The secondary endpoints included the change from baseline of SBMs at Week 2, percentage of patients experiencing SBM within 24 and/or $48 \mathrm{~h}$ of the initial dose, stool consistency, and constipation severity, and adverse events were also evaluated.

Results The 26 and 39 g/day of SK-1202 induced significantly and dose-dependently more increase in SBM at Week 1 than placebo $(p=0.003, p<0.001)$. These groups also showed significant improvements in the secondary
\end{abstract}

Electronic supplementary material The online version of this article (https://doi.org/10.1007/s00535-018-01545-7) contains supplementary material, which is available to authorized users.

Kunio Kasugai

kuku3487@aichi-med-u.ac.jp

1 Division of Gastroenterology, Department of Internal Medicine, Aichi Medical University School of Medicine, 1-1 Yazakokarimata, Nagakute, Aichi 480-1195, Japan

2 Sanwa Kagaku Kenkyusho Co., Ltd., Nagoya, Japan

3 Department of Behavioral Medicine, Tohoku University Graduate School of Medicine, Sendai, Japan endpoints. There were no significant differences in the incidence of adverse drug reactions (ADRs) between the placebo and SK-1202 groups. Gastrointestinal disorder was the most common ADR, and diarrhea developed in 6 patients $(9.7 \%)$ treated with $39 \mathrm{~g} /$ day; however, the symptoms were mild in severity and resolved after followup, dose reduction, or dose suspension. SK-1202 was generally well tolerated up to $39 \mathrm{~g} /$ day.

Conclusion Our results suggest that SK-1202 is useful in Japanese patients with chronic constipation, and optimal dose of SK-1202 is $26 \mathrm{~g} /$ day.

Keywords SK-1202 - Lactulose - Japanese adult · Chronic constipation $\cdot$ Randomized controlled trial

$\begin{array}{ll}\text { Abbreviations } \\ \text { ADRs } & \text { Adverse drug reactions } \\ \text { BSFS } & \text { Bristol Stool Form Scale } \\ \text { IBS-C } & \text { Irritable bowel syndrome with constipation } \\ \text { SBMs } & \text { Spontaneous bowel movements } \\ \text { SOC } & \text { System organ class }\end{array}$

\section{Introduction}

Lactulose is a synthetic disaccharide composed of fructose and galactose. Orally administered lactulose reaches the lower gastrointestinal tract unchanged, where lactulose increases the retention of water and electrolytes by its osmotic effect. Lactulose is broken down by enteric bacteria into organic acids (e.g., lactic and acetic acids) that stimulate bowel motility [1, 2]. Lactulose has been used in many countries for many years as a laxative not only for 
children but also for adults with doses ranging from 10 to $40 \mathrm{~g} /$ day and is recommended as a useful laxative in various therapeutic guidelines, including the "World Gastroenterology Organisation Global Guideline" [3], the "Guidance for the Prevention and Management of Constipation in Adults" [4] by the National Health Service, and the "American Gastroenterological Association Technical Review on Constipation" [5]. Moreover, in Japan, the "Evidence-based clinical practice guideline for chronic constipation 2017" strongly recommended to use osmotic laxatives including lactulose with high level (A) of evidence [6]. Actually lactulose preparations, such as Moni$\operatorname{lac}^{\circledR}$ (syrup/powder), have been marketed in Japan since 1979 for the treatment of pediatric constipation and to induce bowel movement/flatus expulsion after gynecological surgery. However, there was neither a randomized, placebo-controlled, double-blind, parallel-group study for the treatment of adult patients with chronic constipation nor approval of lactulose indicating for chronic constipation in Japan.

We performed a randomized, placebo-controlled, double-blind, parallel-group study of the SK-1202 formulation containing crystalline lactulose as an active ingredient in Japanese adult patients with chronic constipation to evaluate the efficacy and safety of the drug administered twice daily for 2 weeks and to determine the optimal dose for Japanese adult patients.

\section{Methods}

\section{Patients}

Japanese adult patients of either sex, aged $\geq 20$ to $<75$ years, experiencing chronic constipation as defined by the functional constipation without excluding irritable bowel syndrome with constipation (IBS-C) in the Rome III diagnostic criteria [7], were eligible to participate in this study, if they had provided written informed consent after receiving a full explanation of the study's purpose, and met all of the inclusion criteria and none of the exclusion criteria, described below.

Main inclusion criteria were patients had to have fewer than 3 spontaneous bowel movements (SBMs) per week on average before the start of screening assessment and during the 2-week observation period, and to have at least 1 SBMrelated symptom mentioned below from 1 to 3 , which had lasted for at least 6 months.

1. Lumpy or hard stools in at least $25 \%$ of defecations.

2. Sensation of incomplete evacuation for at least $25 \%$ of defecations.

3. Straining during at least $25 \%$ of defecations.
Main exclusion criteria were as follows:

1. Patients with organic constipation;

2. Patients with megacolon or megarectum;

3. Patients with intestinal pseudo-obstruction;

4. Patients who underwent gastrointestinal surgery or an abdominal surgery within 1 year prior to the start of screening assessment, or patients with a history of gastrointestinal resection;

5. Patients with serious renal or hepatic disorders;

6. Patients who have received lactulose; and

7. Patients with galactosemia.

We did not exclude IBS-C patients who had recurrent abdominal pain or discomfort for at least 3 days per month in the last 3 months [7] from patients with chronic constipation. This strategy is supported by the Rome IV criteria as a newer concept of functional gastrointestinal disorders [8]. In the Rome IV criteria, functional constipation and IBS-C were conceptualized as spectrum disorders of the lower gastrointestinal tract [8]. This design was also supported by the evidence-based clinical practice guideline for chronic constipation 2017 in Japan [6].

\section{Drugs}

SK-1202 consisted of a jelly preparation containing $6.5 \mathrm{~g}$ of crystalline lactulose (with a purity of $\geq 97 \%$, hereinafter referred to as "lactulose") in one sachet (Sanwa Kagaku Kenkyusho Co., Ltd., Nagoya, Japan), and the placebo was a jelly preparation that was indistinguishable in appearance and taste from SK-1202 but contained no lactulose (Sanwa Kagaku Kenkyusho Co., Ltd.).

\section{Study design}

This was a multicenter, randomized, placebo-controlled, double-blind, parallel-group study conducted in the 19 medical institutions specialized in gastroenterology in Japan between August 2013 and February 2014 (no. of subjects with informed consent: from 17 to 31 subjects/ institution). The study design is presented in Fig. 1a. The doses of SK-1202 tested in this study were set at 0 (placebo), 13, 26, and $39 \mathrm{~g}$ lactulose/day based on the doses approved overseas for the treatment of adult constipation, ranging from 10 to $40 \mathrm{~g} / \mathrm{day}$ [9]. Patients assigned to the $13 \mathrm{~g} /$ day group received 1 sachet of SK-1202 and 2 sachets of placebo; those to the $26 \mathrm{~g} /$ day group, 2 sachets of SK1202 and 1 sachet of placebo; those to the $39 \mathrm{~g} /$ day group, 3 sachets of SK-1202; and those to the placebo group, 3 sachets of placebo twice daily (morning and evening) orally for 2 weeks. The dosing frequency for Week 2 could be reduced to once daily depending on the patient's symptoms, at the discretion of the investigator/sub- 
a

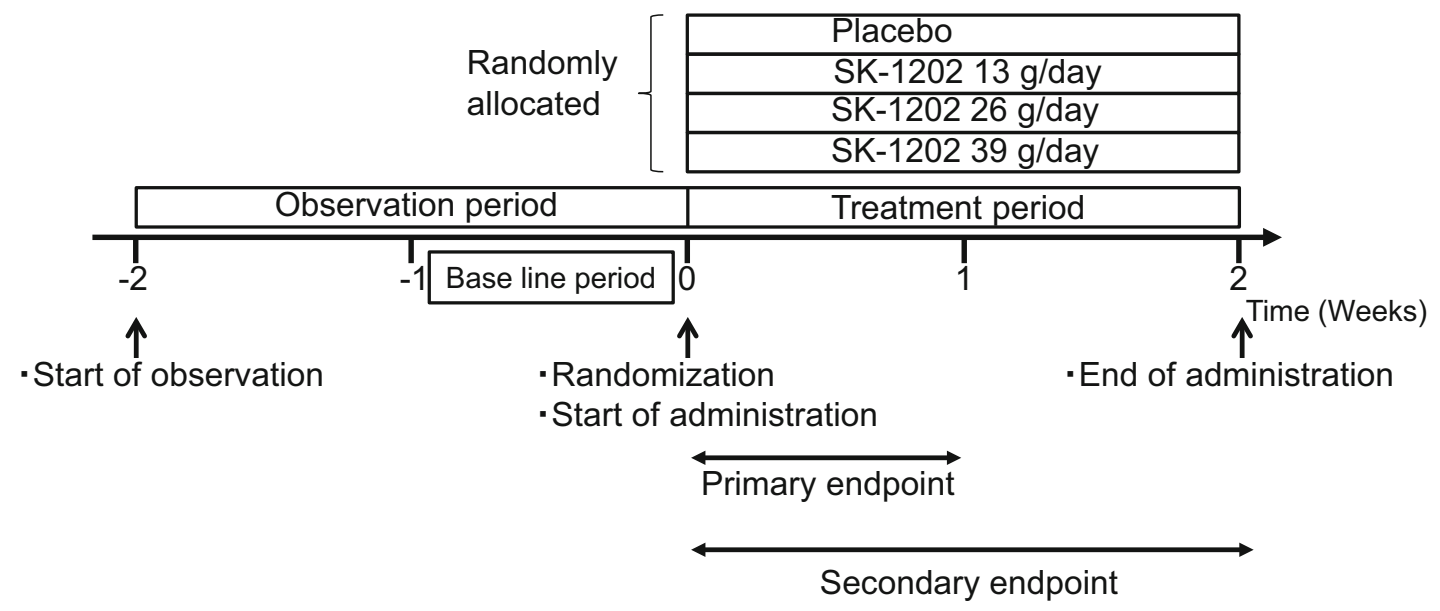

b

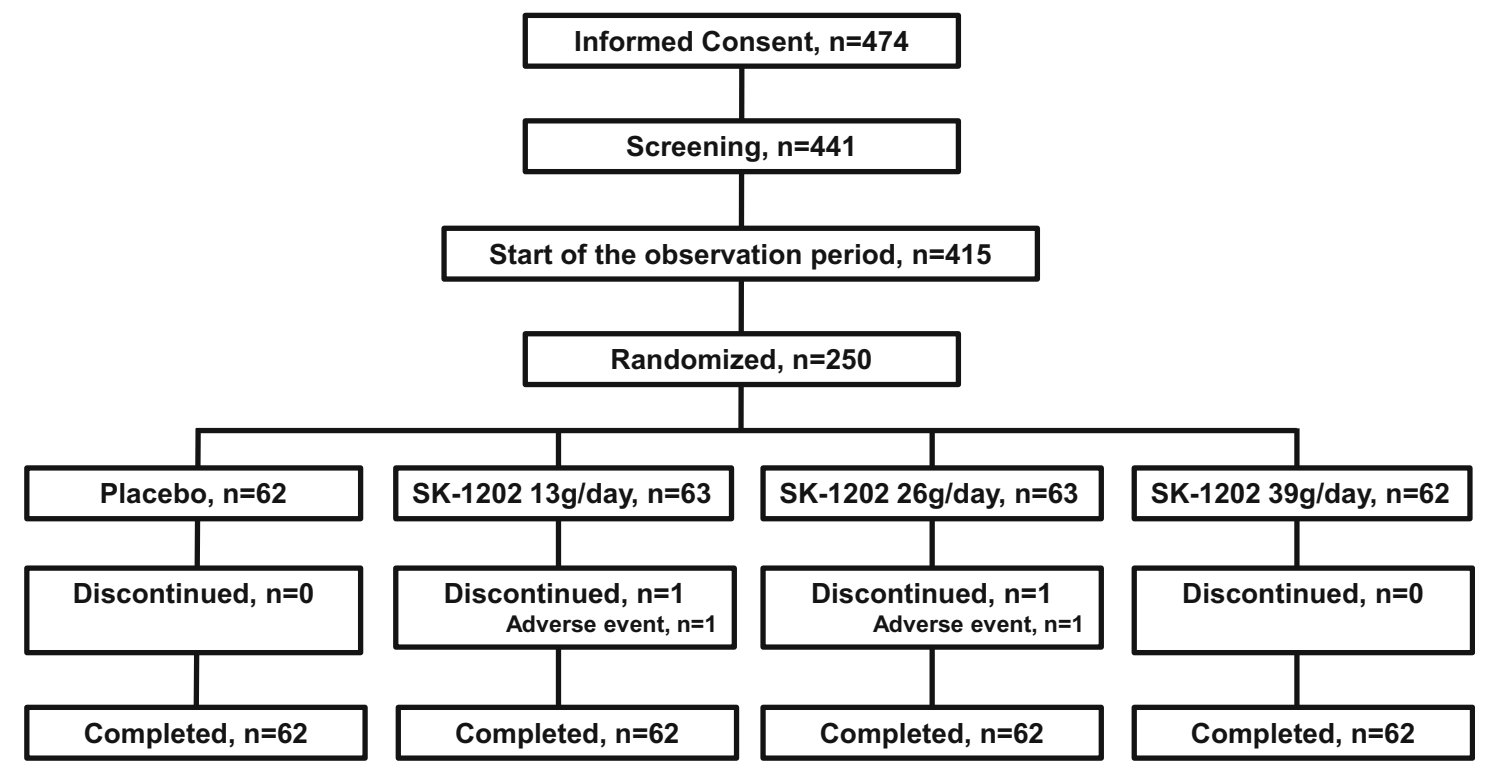

Fig. 1 a Design of the study. b Flow chart of patient enrollment, allocation, and study implementation

investigator. Returning to the originally assigned dose after dose reduction was not permitted.

The sample size in each group was determined as follows: assuming that the change from baseline SBM frequency was increased in the placebo group by $0.98 /$ week in the $26 \mathrm{~g} /$ day group and by $1.5 /$ week in the $39 \mathrm{~g} /$ day group, with a standard deviation of 1.8/week for both groups, based on the data from the overseas study [10, 11], 55 patients in each group would be required to detect significant increases from the placebo group in SBM frequency in the $26 \mathrm{~g} /$ day group and the $39 \mathrm{~g} /$ day group with a power of $80 \%$ at a significance level of 0.05 . Taking into account study discontinuations/dropouts, the sample size necessary for each group was determined to be 62 .
If rescue therapy was required for $24 \mathrm{~h}$ before or $48 \mathrm{~h}$ after the first dose of the study drug, or if the investigator/sub-investigator considered that the continued participation in the study would be difficult due to adverse events, the patient was withdrawn from the study. If no complete defecation occurred for 3 consecutive days in the observation period or in the treatment period, the use of standard rescue therapy with bisacodyl suppository or glycerin enema was provided.

This study was reviewed and approved by the central institutional review board (Mano medical clinic, Approved number: 20130808) and conducted in accordance with the ethical principles that have their origins in the Declaration of Helsinki and in adherence to GCP, the applicable 
regulatory requirements, and the protocol. This study was registered with Japan Pharmaceutical Information Center, number Japic CTI-132219.

\section{Endpoints}

The primary efficacy endpoint was the change from baseline SBM frequency at Week 1 (the mean SBM frequency at Week 1 of the treatment period-the mean SBM frequency at the baseline period (i.e., the last week of the 2-week observation period)) [12]. The weekly number of SBMs was calculated by the following equation. (Number of spontaneous defecation in evaluable days/number of days that can be evaluated) $\times 7$. When patients recorded rescue medication use, the subsequent $24 \mathrm{~h}$ were excluded from calculations of SBM frequency. The secondary efficacy endpoints included the change from baseline SBM frequency at Week 2 (the mean SBM frequency at Week 2 of the treatment period-the mean SBM frequency at the baseline period), the percentage of patients experiencing SBMs within $24 \mathrm{~h}$ or $48 \mathrm{~h}$ after the first dose of the study drug, and the time to the first SBM from the first dose of the study drug. Other assessments at each week of treatment included the stool consistency score [13] and its change, the global assessment score of constipation severity, and the Irritable Bowel Syndrome Quality of Life (IBS-QOL) [14] score.

Stool consistency was categorized into the following 7 types according to the Bristol Stool Form Scale (BSFS) [13]: type 1, separate hard lumps, like nuts (hard to pass); type 2, sausage-shaped but lumpy; type 3, like a sausage but with cracks on its surface; type 4, like a sausage or snake, smooth and soft; type 5, soft blobs with clear cut edges (passed easily); type 6, fluffy pieces with ragged edges, a mushy stool; and type 7, watery, no solid pieces, entirely liquid. The global assessment score of constipation severity was categorized into the following 5 levels: 0 , none (symptoms absent); 1, mild (slight symptoms present); 3 , moderate (constipated, but the symptoms were not severe); 3 , severe (severely constipated, with difficulty in defecating or with faint sensation of the need to defecate; and 4, very severe (extremely constipated, with few defecations or with little sensation of the need to defecate). IBS-QOL was assessed using the Japanese version of the IBS-QOL (acute) [14] and the results were calculated using subscales.

The safety endpoints were adverse events, vital signs, resting 12-lead electrocardiogram, and laboratory test results. The clinical investigators judged the medical event unfavorable to the patient as an adverse event. For example, if the clinical investigators considered that diarrhea caused by softening of feces was preferable for a patient, it was not regarded as an adverse event. Adverse events were coded using the Japanese translation of the Medical Dictionary for Regulatory Activities (MedDRA/J), ver. 16.1. Adverse events for which causal relationship with the study drug could not be ruled out were defined as adverse drug reactions. These safety endpoints, except adverse events, were assessed before the first dose of the study drug and at the completion (or discontinuation) of the 2-week study treatment.

\section{Statistical analyses}

Efficacy analyses were performed on the full analysis set composed of patients who had at least 1 day with evaluable on-treatment efficacy data. Safety analyses were performed on the safety population composed of patients who received at least 1 dose of the study drug. The change from baseline SBM frequency at Week 1, the primary endpoint, was summarized group-wise using descriptive statistics, and pairwise comparisons between each SK-1202-treated group and the placebo group were performed from the highest dose group to the lowest dose group according to the closed testing procedure, using an analysis of covariance (ANCOVA) model including the baseline SBM frequency as a covariate. The dose-response relationship was assessed using the maximum contrast method.

Among the secondary endpoints, the change from baseline SBM frequency at Week 2, the stool consistency score, and the IBS-QOL score were summarized using descriptive statistics and an ANCOVA including the frequency/score at baseline as a covariate. Number and percentages of patients experiencing SBMs within $24 \mathrm{~h}$ and $48 \mathrm{~h}$ after the first dose of the study drug were summarized by groups to compare each SK-1202-treated group with the placebo group using the Fisher's exact probability test. The global assessment score of constipation severity was summarized by week and group to compare each SK-1202treated group with the placebo group using the Wilcoxon rank sum test. Time to the first SBM from the first dose of the study drug was analyzed using Kaplan-Meier curves and compared between each SK-1202-treated group and the placebo group by means of the generalized Wilcoxon test. The median time to the first SBM in each group was determined.

The number of patients experiencing adverse events and adverse drug reactions and their respective incidence rates were calculated for each group to compare each SK-1202treated group and the placebo group using the Fisher's exact probability test.

A $15 \%$ significance level for two-sided tests was used for demographic and other baseline data, a one-sided significance level was set to $2.5 \%$ for the contrast test used to assess the dose-response relationship, and a 5\% 
significance level for two-sided tests was set for other statistical tests, unless otherwise specified.

\section{Results}

\section{Patients analyzed and characteristics}

The disposition of the patients evaluated is presented in Fig. 1b. Excluding 26 screen failures and 165 inclusion/ exclusion criteria violations, 250 patients were randomly assigned to the placebo group (62 patients), the SK-1202 $13 \mathrm{~g} /$ day group (63 patients), the $26 \mathrm{~g} /$ day group (63 patients), or the $39 \mathrm{~g} /$ day group (62 patients). During the study, 2 patients were withdrawn from the study due to adverse drug reactions (mild abdominal distension in 1 patient in the $13 \mathrm{~g} /$ day group and moderate urticaria in 1 patient in the $26 \mathrm{~g}$ /day group). Overall, 248 patients completed the study treatment.

The characteristics of the patients participating in the study are shown in Table 1. Each group had more female patients (77.8-87.1\%), with a mean age of 39.4-43.1 years and a mean body mass index of $20.94-21.99 \mathrm{~kg} / \mathrm{m}^{2}$. The SBM frequency in the baseline period in each group ranged between 1.47 and 1.57/week, with no significant difference among the groups.

There was a significant difference in the presence/absence of previous constipation treatments among the groups (Fisher's exact probability test, $p=0.122$ ). However, no association between the presence/absence of previous constipation treatments and the change from baseline SBM frequency at Week 1, the primary endpoint, was observed. Therefore, the difference in the previous constipation treatments was believed to have no effect on the primary endpoint. In $26 \mathrm{~g} /$ day and $39 \mathrm{~g}$ /day groups, there was a significant difference from control group in change from the baseline SBM in the patients with the presence or absence of treatment history of constipation. It is considered that treatment with SK-1202 improved constipation in comparison with previous treatment.

\section{Efficacy}

The mean change from baseline SBM frequency at Week 1 , the primary endpoint, was $2.17 /$ week in the $13 \mathrm{~g} /$ day group, 3.77/week in the $26 \mathrm{~g} /$ day group, and 5.05/week in the $39 \mathrm{~g} /$ day group; whereas, it was $2.05 /$ week in the placebo group. An ANCOVA showed that the increases in the SBM frequency in the 26 g/day group and in the 39 g/day group were significantly higher than in the placebo group ( $p=0.003$ and $p<0.001$, respectively) (Fig. 2a). In the assessment of the dose-response relationship, a contrast test using contrast coefficient $(-3,-3,1,5)$ for treatment groups (placebo, SK-1202 $13 \mathrm{~g} /$ day, $26 \mathrm{~g} /$ day, and $39 \mathrm{~g} /$ day) provided the maximum test statistic $(t=5.877$, $p<0.001)$. It indicated that the dose-response relationship of SK-1202 for the primary endpoint was apparent at $26 \mathrm{~g} /$ $\mathrm{kg}$ or higher dose; whereas, the response plateaued between the placebo group and the $13 \mathrm{~g} /$ day group. There was no major difference in change of SBM frequency between all the patients and the patients without rescue medication (data not shown).

Similar to the primary endpoint, the change from baseline SBM frequency at Week 2 increased as the dose increased, and significant differences from the placebo group were found for the $26 \mathrm{~g} /$ day group and the $39 \mathrm{~g} /$ day group ( $p=0.007$ and $p<0.001$, respectively) (Fig. 2b). The percentage of patients experiencing the first SBM within $24 \mathrm{~h}$ after the first dose of the study drug rose as the dose increased, and it was significantly higher in the $26 \mathrm{~g} /$ day and in the $39 \mathrm{~g} /$ day groups $(65.1 \%$ and $67.7 \%$, respectively) than in the placebo group ( $p=0.001$ and $p<0.001$, respectively). Similarly, the percentage of patients experiencing the first SBM within $48 \mathrm{~h}$ after the first dose of the study drug rose as the dose increased, and it was significantly higher in the $26 \mathrm{~g}$ /day group and in the $39 \mathrm{~g} /$ day group $(82.5 \%$ and $85.5 \%$, respectively) than in the placebo group ( $p=0.022$ and $p=0.007$, respectively) (Fig. 2c).

The time to the first SBM from the first dose of the study drug is presented in Fig. 3.

The time to the first SBM was significantly shorter in the $26 \mathrm{~g} /$ day and in the $39 \mathrm{~g} /$ day groups than in the placebo group ( $p=0.003$ and $p<0.001$, respectively). The median time to the first SBM was $24.50 \mathrm{~h}$ [95\% confidence interval (CI), 14.33-27.77] in the $13 \mathrm{~g} /$ day group, $10.00 \mathrm{~h}(95 \% \mathrm{CI}$ $6.08-17.00)$ in the $26 \mathrm{~g} /$ day group, and $10.33 \mathrm{~h}(95 \% \mathrm{CI}$ 5.45-22.58) in the $39 \mathrm{~g} /$ day group, as compared to $27.98 \mathrm{~h}$ (95\% CI 24.33-48.00) in the placebo group; thus, it was significantly shorter in the $26 \mathrm{~g} /$ day group and the $39 \mathrm{~g} /$ day group than in the placebo group (Fig. 3).

BSFS was close to ideal stool consistency of "3-5" in the 26/day and in the $39 \mathrm{~g}$ /day groups (Fig. 4a). And the changes in the stool consistency from the baseline scale at Week 1 in the $26 \mathrm{~g} /$ day group and the $39 \mathrm{~g} /$ day group significantly improved compared to the placebo group ( $p<0.02$ and $p<0.001$, respectively). The significant improvements observed in the $26 \mathrm{~g} /$ day and the $39 \mathrm{~g} /$ day groups persisted up to Week 2 ( $p<0.001$ for both groups, Fig. 4b).

The global assessment scores of constipation severity are shown in Fig. 5. There was no statistically significant difference in the severity of constipation between placebo group and $13 \mathrm{~g} /$ day, $26 \mathrm{~g} /$ day and $39 \mathrm{~g} /$ day groups at baseline period. The proportion of patients with "symptoms absent" was 1 of 62 patients in the placebo group, 0 
Table 1 Patient characteristics and baseline (safety population)

\begin{tabular}{|c|c|c|c|c|c|}
\hline \multirow[t]{2}{*}{ Characteristics } & \multirow{2}{*}{$\begin{array}{l}\text { Placebo } \\
n=62\end{array}$} & \multicolumn{3}{|l|}{ SK-1202 } & \multirow[t]{2}{*}{$p$ value* } \\
\hline & & $\begin{array}{l}13 \text { g/day } \\
n=63\end{array}$ & $\begin{array}{l}26 \mathrm{~g} / \text { day } \\
n=63\end{array}$ & $\begin{array}{l}39 \mathrm{~g} / \text { day } \\
n=62\end{array}$ & \\
\hline \multicolumn{6}{|l|}{ Sex, $n(\%)$} \\
\hline Male & $9(14.5)$ & $9(14.3)$ & $14(22.2)$ & $8(12.9)$ & \multirow[t]{2}{*}{$0.505^{\mathrm{a}}$} \\
\hline Female & $53(85.5)$ & $54(85.7)$ & $49(77.8)$ & $54(87.1)$ & \\
\hline \multicolumn{6}{|l|}{ Age, years } \\
\hline Mean $\pm \mathrm{SD}$ & $42.3 \pm 11.6$ & $39.4 \pm 12.3$ & $42.8 \pm 12.7$ & $43.1 \pm 11.0$ & $0.286^{\mathrm{b}}$ \\
\hline \multicolumn{6}{|l|}{ BMI, $\mathrm{kg} / \mathrm{m}^{2}$} \\
\hline Mean \pm SD & $20.94 \pm 3.19$ & $21.47 \pm 2.91$ & $21.99 \pm 3.99$ & $21.55 \pm 3.11$ & $0.369^{\mathrm{b}}$ \\
\hline \multicolumn{6}{|c|}{ Duration of constipation (months) } \\
\hline Mean \pm SD & $217.9 \pm 143.7$ & $198.5 \pm 145.9$ & $192.4 \pm 135.9$ & $187.0 \pm 139.9$ & $0.638^{\mathrm{b}}$ \\
\hline \multicolumn{6}{|c|}{ History of treatment for constipation, $n(\%)$} \\
\hline No & $29(46.8)$ & $42(66.7)$ & $35(55.6)$ & $31(50.0)$ & \multirow[t]{2}{*}{$0.122^{\mathrm{a}}$} \\
\hline Yes & $33(53.2)$ & $21(33.3)$ & $28(44.4)$ & $31(50.0)$ & \\
\hline \multicolumn{6}{|c|}{ Constipation-predominant IBS, $n(\%)$} \\
\hline No & $55(88.7)$ & $59(93.7)$ & $60(95.2)$ & $56(90.3)$ & \multirow[t]{2}{*}{$0.500^{\mathrm{a}}$} \\
\hline Yes & $7(11.3)$ & $4(6.3)$ & $3(4.8)$ & $6(9.7)$ & \\
\hline \multicolumn{6}{|c|}{ The frequency of SBMs at baseline, time/week } \\
\hline Mean \pm SD & $1.47 \pm 0.79$ & $1.50 \pm 0.74$ & $1.57 \pm 0.61$ & $1.55 \pm 0.64$ & $0.831^{\mathrm{b}}$ \\
\hline \multicolumn{6}{|c|}{$\begin{array}{l}S D \text { standard deviation, } B M I \text { body mass index, } I B S \text { irritable bowel syndrome, } S B M \text { spontaneous bowel } \\
\text { movement }\end{array}$} \\
\hline \multicolumn{6}{|c|}{$*$ The two-sided level of significance is $15 \%$} \\
\hline \multicolumn{6}{|c|}{ âFisher's Exact Test } \\
\hline \multicolumn{6}{|c|}{ bone-way ANOVA } \\
\hline
\end{tabular}

of 63 patients in the $13 \mathrm{~g}$ /day group, 1 of 63 patients in the $26 \mathrm{~g} /$ day group, and 0 of 62 patients in the $39 \mathrm{~g} /$ day group in the baseline period, which increased dose dependently to 4 of 62,6 of 63,10 of 63 , and 19 of 62 patients, respectively, at Week 2 . The global assessment score of constipation severity at Weeks 1 and 2 in the $26 \mathrm{~g}$ /day group and in the $39 \mathrm{~g} /$ day group improved more significantly than in the placebo group $(p<0.01$ and $p<0.001$ at Week 1 , $p<0.001$ for both groups at Week 2).

The change from baseline IBS-QOL-J, acute score at Week 2 was analyzed using an ANCOVA including the score at baseline as a covariate. The differences in least squares mean relative to the placebo group revealed a trend toward improvement in the subscales of healthy worry and food avoidance in the $26 \mathrm{~g} / \mathrm{day}$ group and significant improvements in the subscales of body image, healthy worry, food avoidance, and overall $(p=0.003, p<0.001$, $p=0.022$, and $p=0.028$, respectively) in the $39 \mathrm{~g} / \mathrm{day}$ group (Supplementary Fig. S1).

\section{Safety}

No deaths were reported, and no patients experienced any other serious adverse events or adverse drug reactions. In addition, no patients experienced any severe adverse events. Study treatment was discontinued in 1 patient due to adverse drug reactions in the $13 \mathrm{~g} /$ day group (1.6\%, abdominal distension [mild, resolved]) and in 1 patient in the $26 \mathrm{~g} /$ day group (1.6\%, urticaria [moderate, resolved]), with no discontinuations due to adverse drug reactions in the placebo group and the $39 \mathrm{~g} /$ day group. The numbers of patients with adverse drug reactions and their respective incidence rates are shown in Table 2. There were no significant differences between the SK-1202-treated groups and the placebo group. The adverse drug reactions reported in $\geq 2 \%$ of patients in any of the SK-1202-treated groups were diarrhea, abdominal pain, abdominal distension, and gastrointestinal sounds abnormal, all of which were classified under the System Organ Class (SOC) of "gastrointestinal disorders". In the $39 \mathrm{~g} /$ day group, a total of 13 patients $(21.0 \%)$ experienced these adverse drug reactions, and in particular, diarrhea was reported in more patients $[6$ patients $(9.7 \%)$ ]. All these adverse drug reactions were mild in severity and resolved or improved with no treatment for the reactions, by study treatment suspension, or dose reduction. 
Fig. 2 Dose-related effects of SK-1202 on spontaneous bowel movements (SBMs) in patients with chronic constipation. a Changes in SBMs from baseline at Week 1. b Change in SBMs from baseline at Week 2. c Percentage of patients who had initial SBM within 24 or $48 \mathrm{~h}$ after initiation of SK-1202 treatment. The columns and bars represent mean \pm standard deviation in $\mathbf{a}$ and $\mathbf{b}$. The columns and numbers represent mean of percentage of patients in c. Significant differences in changes in SBMs from baseline based on ANCOVA with average weekly SBMs at baseline as covariate:

$* p<0.05, * * p<0.01$,

$* * * p<0.001$ vs. placebo.

Significant differences in the percentage of patients with initial SBM based on Fisher's Exact Test, ${ }^{\#} p<0.05$, ${ }^{\# \# p}<0.01,{ }^{\# \#} p<0.001$ vs placebo

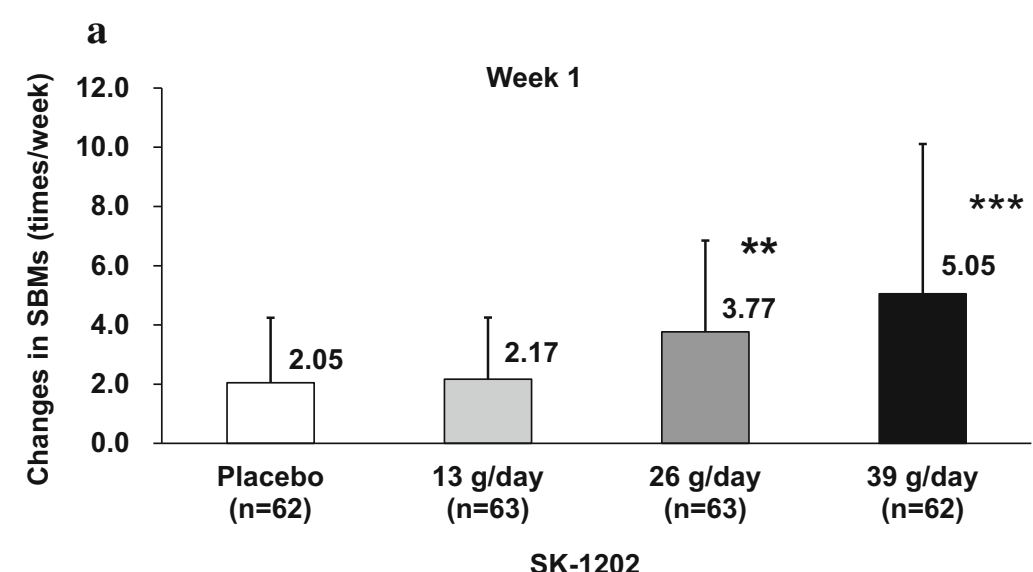

SK-1202
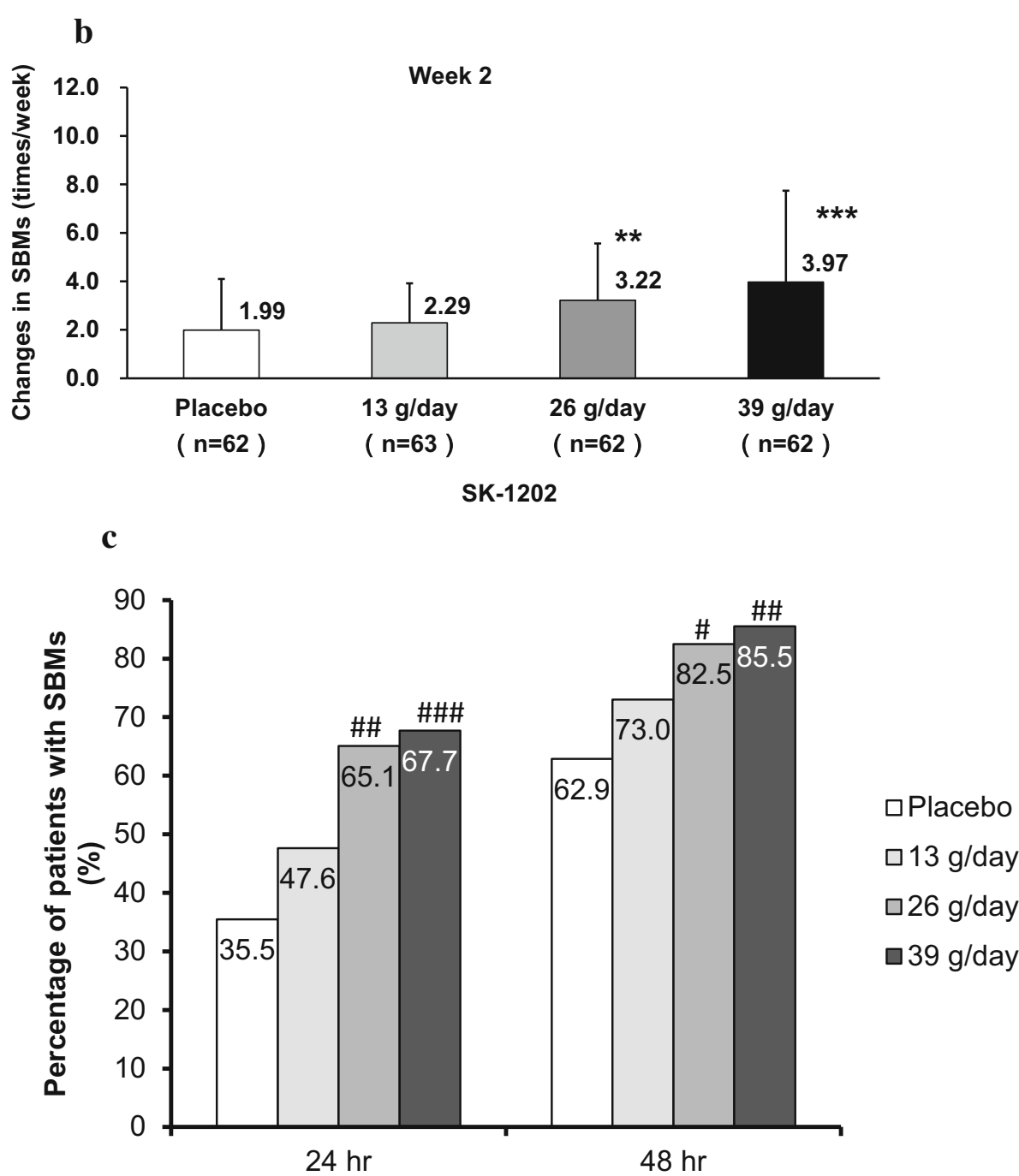

\section{Discussion}

This is the first study that lactulose is actually effective without any serious adverse events for patients with chronic constipation in Japan. Lactulose is recommended as a useful laxative by different guidelines for the treatment of constipation [3-6] and is widely used overseas. In Japan, however, it has not been approved for the treatment of adult constipation. Bass et al. administered lactulose at a dose of $40 \mathrm{~g} /$ day for 1 week to evaluate its effects on stool 


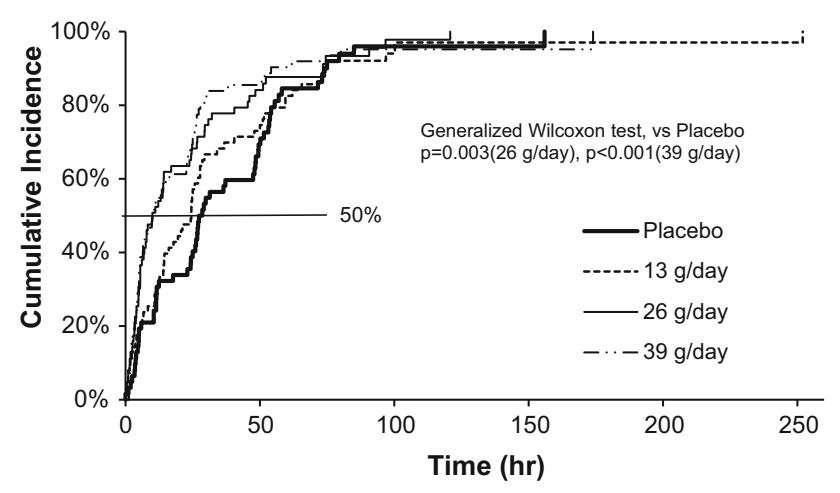

Fig. 3 Kaplan-Meier curve for time (hours) to initial spontaneous bowel movement incidence in each group. Time (hour) represents required number of hours to induce an initial spontaneous bowel movement (SBM) after the first SK-1202 dose. Cumulative incidence represents ratio of patients with initial SBM

frequency [11]. The stool frequency in the lactulose group increased from 1.6/week at baseline to 4.5/week at Week 1; while it, in the placebo group, increased from 1.4/week at baseline to 2.8 /week at Week 1 . The adverse events reported in the lactulose group were abdominal discomfort, nausea, severe diarrhea, and excessive flatulence. The usual adult dose of lactulose approved overseas for the treatment of chronic constipation is $10-40 \mathrm{~g} / \mathrm{day}$. We, therefore, performed the first randomized, placebo-controlled, double-blind, parallel-group study in Japanese adult patients with chronic constipation to evaluate the efficacy and safety and to determine the optimal dose of SK-1202, a lactulose preparation, which was administered at a dose of $13 \mathrm{~g} /$ day, $26 \mathrm{~g} /$ day or $39 \mathrm{~g} /$ day twice daily for 2 weeks.

The change from baseline SBM frequency at Week 1, the primary endpoint, was greater in the $26 \mathrm{~g} /$ day group and the $39 \mathrm{~g} /$ day group than in the placebo group, indicating a dose-response relationship between the $26 \mathrm{~g} /$ day and $39 \mathrm{~g} /$ day. Our dose of lactulose with $39 \mathrm{~g} /$ day was almost comparable dose in the previous study [11]. There was no major difference in change of SBM frequency between all the patients and the patients without rescue medication. Therefore, the usage of rescue medication did not affect the results. These results supported the efficacy of SK-1202 administered in doses of $26 \mathrm{~g} /$ day or higher in treating adult constipation. The change from baseline SBM frequency at Week 2 was also greater in the $26 \mathrm{~g} / \mathrm{day}$ and $39 \mathrm{~g} /$ day groups than in the placebo group. The changes in the $26 \mathrm{~g} /$ day group were similar between Week 1 and Week 2, but in the $39 \mathrm{~g} /$ day group, the change at Week 1 was higher than it at Week 2. In the $39 \mathrm{~g}$ /day group, some patients who experienced diarrhea at Week 1 reduced daily dose at Week 2. Therefore, we considered that the change from baseline SBM frequency in $39 \mathrm{~g} /$ day at Week 1 might
Fig. 4 a Serial changes in BSFS in each group. b Changes in stool consistency from baseline by BSFS. BSFS Bristol Stool Form Scale. a The stool consistency was based on BSFS. The columns and numbers represent the mean BSFS, and the bars represent the standard deviation. b Difference in the change in BSFS was analyzed with the use of ANCOVA model with mean weekly score at baseline as covariate $* * p<0.01, * * * p<0.001$ vs placebo. The markers and bars represent mean and standard deviation

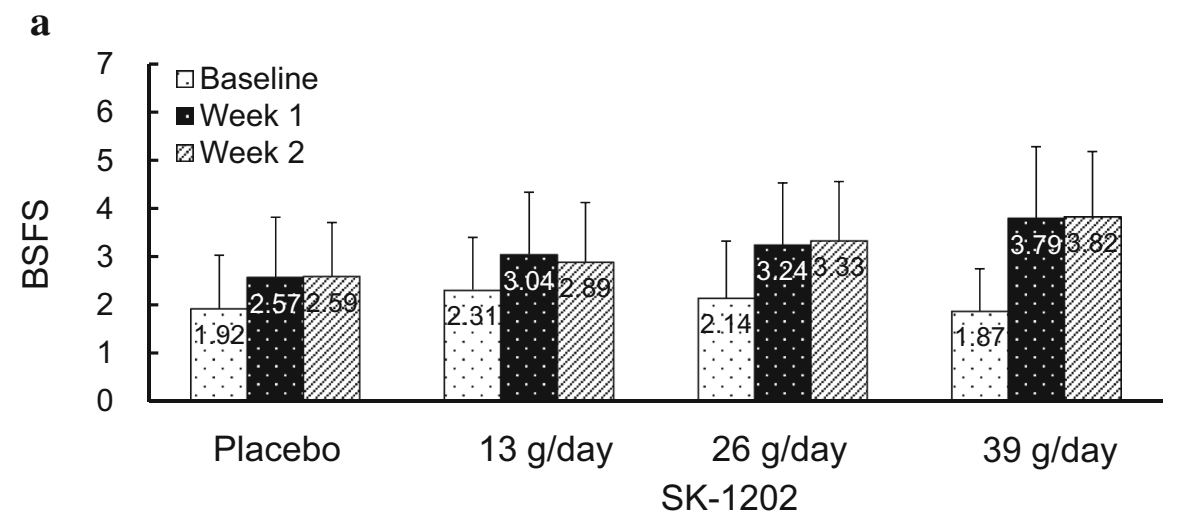

b

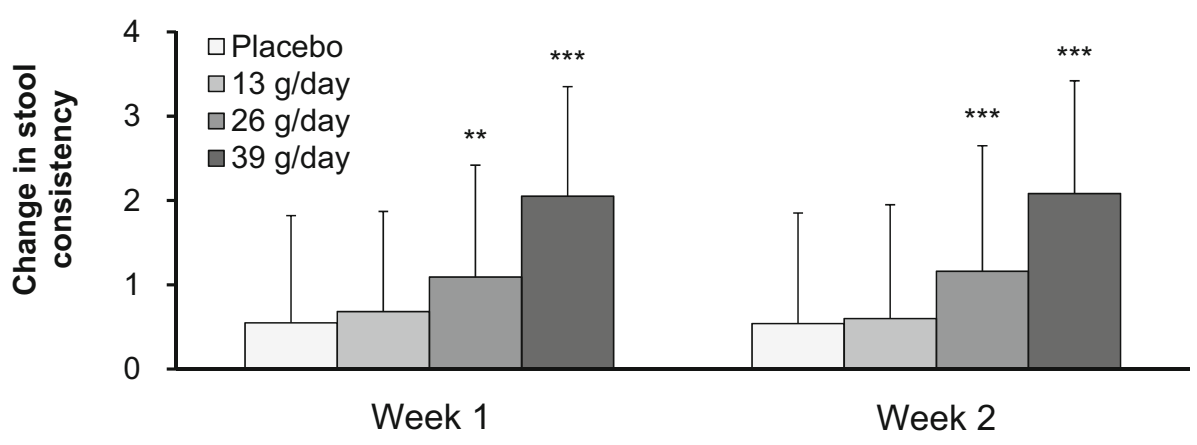


Fig. 5 Serial changes from baseline in the number of patients with constipation stratified by severity. Top, each square represents severity of constipation. a The data for one patient were missing in week 2 . $* * p<0.01, * * * p<0.001 \mathrm{vs}$. placebo (by Wilcoxon rank sum test)

Table 2 Summary of adverse drug reactions in each group $\square$ None $\square$ Mild $\square$ Moderate $\square$ Severe $\square$ Very severe

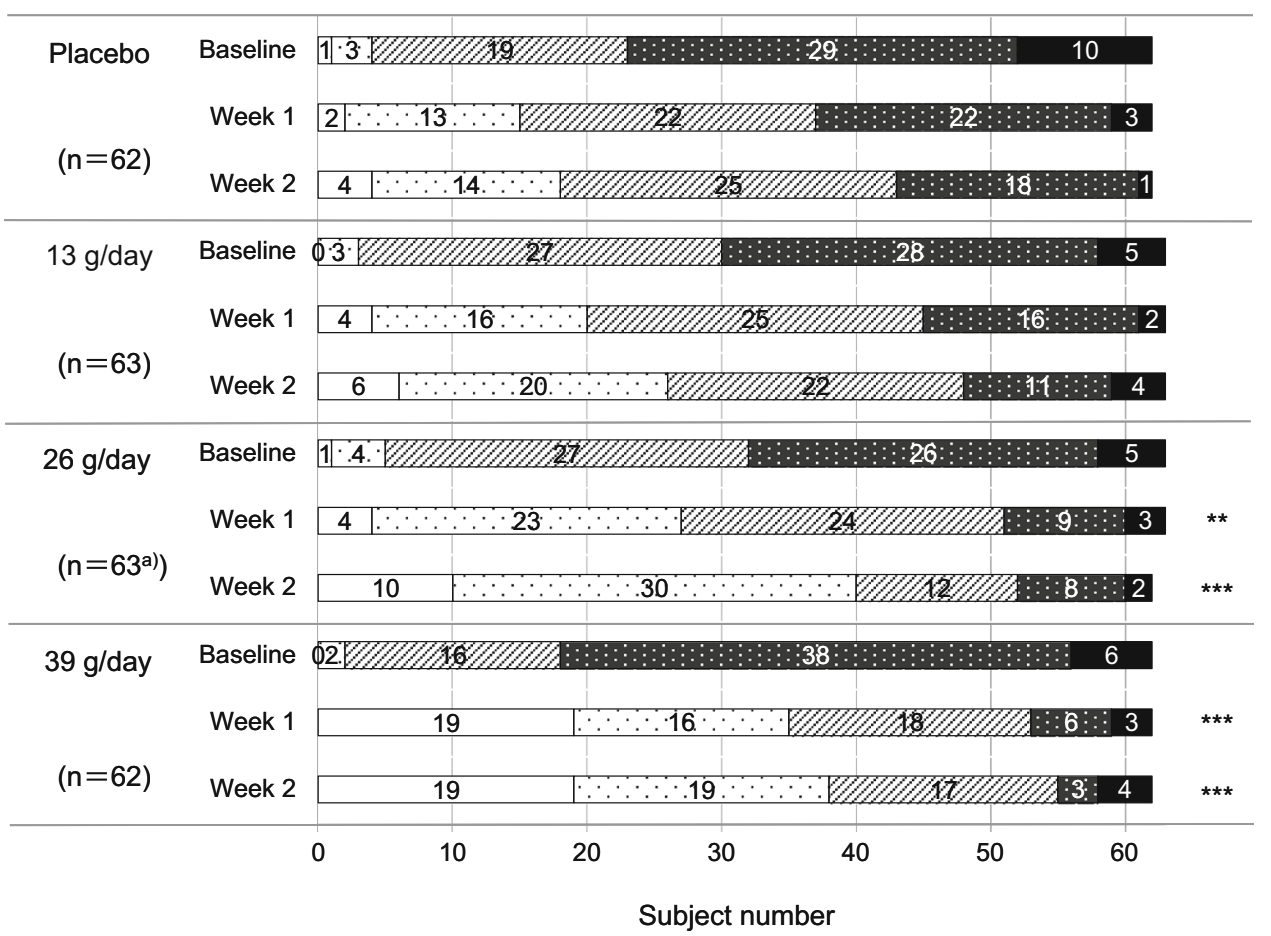

\begin{tabular}{|c|c|c|c|c|}
\hline & \multirow{2}{*}{$\begin{array}{l}\text { Placebo, } n(\%) \\
n=62\end{array}$} & \multicolumn{3}{|c|}{ SK-1202, $n(\%)$} \\
\hline & & $\begin{array}{l}13 \mathrm{~g} / \text { day } \\
n=63\end{array}$ & $\begin{array}{l}26 \mathrm{~g} / \text { day } \\
n=63\end{array}$ & $\begin{array}{l}39 \text { g/day } \\
n=62\end{array}$ \\
\hline At least one ADR & $6(9.7)$ & $2(3.2)$ & $4(6.3)$ & $13(21.0)$ \\
\hline \multicolumn{5}{|l|}{ Gastrointestinal disorders $^{\mathrm{a}}$} \\
\hline Abdominal distension & $0(0.0)$ & $1(1.6)$ & $1(1.6)$ & $2(3.2)$ \\
\hline Abdominal pain & $2(3.2)$ & $0(0.0)$ & $1(1.6)$ & $2(3.2)$ \\
\hline Diarrhea & $0(0.0)$ & $0(0.0)$ & $0(0.0)$ & $6(9.7)$ \\
\hline Gastrointestinal sounds abnormal & $0(0.0)$ & $0(0.0)$ & $1(1.6)$ & $2(3.2)$ \\
\hline \multicolumn{5}{|l|}{ Investigations $^{\mathrm{a}}$} \\
\hline Protein total decreased & $2(3.2)$ & $0(0.0)$ & $0(0.0)$ & $0(0.0)$ \\
\hline
\end{tabular}

$A D R$ adverse drug reaction

${ }^{\mathrm{a}}$ Adverse drug reactions reported by more than $2 \%$ of subjects in any group are shown be caused by dosing of the surplus amount of lactulose to the subjects.

The percentage of patients experiencing SBMs within $24 \mathrm{~h}$ and $48 \mathrm{~h}$ after the first dose of the study drug, the time to the first SBM from the first dose, global assessment score of constipation severity, and the change in stool consistency showed a more improvement in the $26 \mathrm{~g} / \mathrm{day}$ group and in the $39 \mathrm{~g} /$ day group than in the placebo group. With regard to the safety profile of SK-1202, there were no differences in the number of patients or in the incidence rate of adverse drug reactions among the SK-1202-treated groups. In the $39 \mathrm{~g} /$ day group, the adverse drug reactions of diarrhea, gastrointestinal sounds abnormal, abdominal distension, and abdominal pain, all of which were classified under the SOC of "gastrointestinal disorders", were frequently reported, and in particular, diarrhea occurred in more patients [6 patients $(9.7 \%)$ ]. The earlier randomized controlled trial of lactulose for elderly patients with chronic constipation reported that administration of $8-30 \mathrm{ml} / \mathrm{day}$ of $50 \%$ lactulose did not induce diarrhea [15]. In this study, all adverse drug reactions were mild, and resolved or improved with no treatment for the reactions, or by study treatment suspension or dose reduction. Five patients in the $39 \mathrm{~g} /$ day group required dose reduction due to diarrhea, 
gastrointestinal sounds abnormal, or other reasons, suggesting that the dose of $39 \mathrm{~g} /$ day may be supratherapeutic and should be reduced for some patients.

There have been several studies evaluating the efficacy and safety of stimulant laxatives in patients with chronic constipation as defined by the Rome III diagnostic criteria. The percentage of patients experiencing their first SBM within $24 \mathrm{~h}$ after the first dose of picosulfate was 69\% [16], which was not largely different from the percentage obtained in the SK-1202 (65.1\%). The mean time to the first SBM from the first dose of bisacodyl was $12 \mathrm{~h}$ [17], which was similar to the time observed in the SK-1202 $(10 \mathrm{~h})$. The incidence rate of adverse drug reactions, such as diarrhea, in patients receiving 4-week bisacodyl therapy was $63.6 \%$ (157 of 247 patients); whereas, it was $6.3 \%$ in patients receiving $26 \mathrm{~g} /$ day of SK-1202 for 2 weeks in this study, suggesting that the drugs have different safety profiles.

At the time of beginning of this study, lubiprostone was the only agent for which the clinical effect and safety were proven with the recent design of randomized double-blind controlled trial in Japan [12]. Lubiprostone consists of new action mechanism and selectively activates the type 2 chloride channel, which increases fluid secretion in the intestinal apical cell membrane. On the other hand, lactulose reaches the lower gastrointestinal tract unchanged, where lactulose increases the retention of water and electrolytes by its osmotic effect. The changes from baseline SBM frequency at Weeks 1 and 2 in Japanese patients with chronic idiopathic constipation treated with the recommended clinical dose ( $48 \mu \mathrm{g} /$ day) of lubiprostone, a secretagogue, were 3.66/week and 2.74/week, respectively [12]; whereas, the changes were 3.24/week and 3.33/week observed in the $26 \mathrm{~g} /$ day SK-1202-treated group. The percentage of patients experiencing SBMs within $24 \mathrm{~h}$ after the first dose of SK-1202 $26 \mathrm{~g} /$ day group was $65.1 \%$ relative to $35.5 \%$ in the placebo group. This percentage was considered to be comparable with $58.1 \%$ relative to $30.6 \%$ in the placebo group as the percentage of patients experiencing SBMs within $24 \mathrm{~h}$ after the first dose of lubiprostone.

Abe et al. reported the safety of lubiprostone in 133 patients with chronic constipation (average age: 65 years old) who were given at $24 \mu \mathrm{g}$ twice a day [18]. In their study, the incidence of experienced adverse drug reactions (ADRs) in the first 2 weeks after administration was $41.4 \%$ (55/133 patients), and nausea and diarrhea occurred at $24 \%$ and $17 \%$, respectively. In our study with SK-1202, incidence of experienced ADRs was $6.3 \%$ in the $26 \mathrm{~g} /$ day group and $21.0 \%$ in the $39 \mathrm{~g} /$ day group. Nausea and diarrhea occurred only in the $39 \mathrm{~g} /$ day group, and incidence of nausea and diarrhea was $1.6 \%$ (1/62 patients) and 9.7\% (6/ 62 patients), respectively. We consider the reason for this difference as follows. SK-1202 has osmotic effect in the lower gastrointestinal tract, and enhances bowel motility stimulated by organic acid to which lactulose is broken down by enterobacteria. On the other hand, lubiprostone has mechanism of action enhancing fluid secretion directly in the intestinal apical cell membrane. Therefore, the ADR of SK-1202 may be relatively less frequent than that of lubiprostone.

There were several limitations in this study. First, patients with IBS-C defined by the Rome III diagnostic criteria [7] were eligible for participation. However, the proportion of patients with IBS-C enrolled in the study with respect to the entire study population was low: 7 of 62 patients $(11.3 \%)$ in the placebo group, 4 of 63 patients $(6.3 \%)$ in the $13 \mathrm{~g} /$ day group, 3 of 63 patients $(4.8 \%)$ in the $26 \mathrm{~g} /$ day group, and 6 of 62 patients $(9.7 \%)$ in the $39 \mathrm{~g} / \mathrm{day}$ group (Table 1). Therefore, the effects of SK-1202 on IBS$\mathrm{C}$ could not be determined in this study and would require further investigation. Second, ratio of active compound: placebo was not 1:1 in this study. However, this is the first randomized controlled trial of lactulose in Japanese patients with chronic constipation. We consider that the design of this study is enough to support the Japanese evidence of lactulose as effective agents for chronic constipation as was previously and internationally meta-analyzed [19].

In conclusion, SK-1202, when administered twice daily for 2 weeks at a dose of $26 \mathrm{~g} / \mathrm{day}$ or $39 \mathrm{~g} /$ day to Japanese adult patients with chronic constipation, was more effective than placebo, and a dose-response relationship was demonstrated between the $26 \mathrm{~g} /$ day and $39 \mathrm{~g} /$ day dosages. SK-1202 was generally well tolerated, except for the increased incidence of diarrhea in the $39 \mathrm{~g}$ /day group. The optimal dose of SK-1202 in the treatment of chronic constipation was, therefore, estimated to be $26 \mathrm{~g} / \mathrm{day}$. This dose falls within the range of the doses approved overseas for the treatment of adult constipation (10-40 g/day), and treatment with SK-1202 caused no serious or severe adverse drug reactions specific to Japanese patients in this study, indicating no ethnic difference in the efficacy and safety of lactulose. Based on these results, SK-1202 is expected to be a useful drug in the treatment of adult constipation, both for its efficacy and safety.

Acknowledgements The authors thank that the investigators and patients in the following medical institution for participating in this study. Asahi Clinic, Kyoai Clinic, Tasaka Memorial Clinic, Akasaka Chuo Clinic, Ueda Gastrointestinal Clinic, Ebisu Garden Place Clinic, Hirakawa Icho Clinic, Kobori Clinic, Kameido Minamiguchi Clinic, Banno Clinic, Ankoh Medical Clinic, Marine Clinic, Hokusetsu General Hospital, Morikawa Clinic (Osaka), Morita Internal Medicine and Endoscopy, Murano Clinic, Morikawa Clinic (Hirakata), Kuroda Clinic and Kitamura Clinic. 
Author contributions Guarantor of the article: KK Specific author contributions: KK, HI, NK, and SF designed the study, assessed the data, performed statistical analyses, and wrote the manuscript. AY involved in the analyses, interpreted the data, and wrote the manuscript. All authors have approved the final version of the article.

Funding This study was funded by the Grants by Sanwa Kagaku Kenkyusho Co., Ltd.

\section{Compliance with ethical standards}

Ethical approval This study was fully approved by the central institutional review board/ethics committee of participated organizations.

Conflict of interest Kunio Kasugai and Shin Fukudo declare that there is no actual conflict of interest but that potential conflict of interest is present as contracted medical consultant which has been appropriately managed. Hisakazu Iwai, Noboru Kuboyama and Aya Yoshikawa are employees of Sanwa Kagaku Kenkyusho Co., Ltd. and there is no actual conflict of interest.

Open Access This article is distributed under the terms of the Creative Commons Attribution 4.0 International License (http://crea tivecommons.org/licenses/by/4.0/), which permits unrestricted use, distribution, and reproduction in any medium, provided you give appropriate credit to the original author(s) and the source, provide a link to the Creative Commons license, and indicate if changes were made.

\section{References}

1. Hammer HF, Santa Ana CA, Schiller LR, et al. Studies of osmotic diarrhea induced in normal subjects by ingestion of polyethylene glycol and lactulose. J Clin Investig. 1989;84: 1056-62.

2. Bircher J, Müller J, Guggenheim P, et al. Treatment of chronic portal-systemic encephalopathy with lactulose. Lancet. 1966;1: 890-2.

3. Lindberg G, Hamid SS, Malfertheiner P, et al. World Gastroenterology Organisation global guideline: constipation-a global perspective. J Clin Gastroenterol. 2011;45:483-7.

4. Guidance for the prevention and management of constipation in adults. Version 4. NHS: 2018. http://www.dudleyformulary.nhs. uk/download/8/constipation-in-adults-prevention-and-manage ment-guidelines. Accessed 12 Nov 2018.
5. Bharucha AE, Pemberton JH, Locke GR. American Gastroenterological Association technical review on constipation. Gastroenterology. 2013;144:218-38.

6. Research Society for the diagnosis and treatment of chronic constipation/Affiliated to The Japanese Society of Gastroenterology. Evidence-based clinical practice guideline for chronic constipation 2017. Tokyo: Nankodo; 2017. p. 66-8.

7. Longstreth GF, Thompson WG, Chey WD, et al. Functional bowel disorders. Gastroenterology. 2006;130:1480-91.

8. Mearin F, Lacy BE, Chang L, et al. Bowel disorders. Gastroenterology. 2016;150:1393-407.

9. Harry T, Rick P, David C, et al. Physicians' desk reference 2017. 71st ed. New Jersey: PDR Network; 2017. p. S-481 (ISBN 978-156363-838-1).

10. Sanders JF. Lactulose syrup assessed in a double-blind study of elderly constipated patients. J Am Geriatr Soc. 1978;26:236-9.

11. Bass P, Dennis S. The laxative effects of lactulose in normal and constipated subjects. J Clin Gastroenterol. 1981;3(suppl. 1):23-8.

12. Fukudo S, Hongo M, Kaneko H, et al. Lubiprostone increases spontaneous bowel movement frequency and quality of life in patients with chronic idiopathic constipation. Clin Gastroenterol Hepatol. 2015;13:294-301.

13. Lewis SJ, Heaton KW. Stool form scale as a useful guide to intestinal transit time. Scand J Gastroenterol. 1997;32:920-4.

14. Kanazawa M, Drossman DA, Shinozaki M, et al. Translation and validation of a Japanese version of the irritable bowel syndromequality of life measure (IBS-QOL-J). BioPsychoSocial Med. 2007;1:6.

15. Wesselius-De Casparis A, Braadbaart S, Bergh-Bohlken GE, Mimica M. Treatment of chronic constipation with lactulose syrup: results of a double-blind study. Gut. 1968;9:84-6.

16. Mueller-Lissner S, Kamm MA, Wald A, et al. Multicenter, 4-week, double-blind, randomized, placebo-controlled trial of sodium picosulfate in patients with chronic constipation. Am J Gastroenterol. 2010;105:897-903.

17. Kamm MA, Mueller-Lissner S, Wald A, et al. Oral bisacodyl is effective and well-tolerated in patients with chronic constipation. Clin Gastroenterol Hepatol. 2011;9:577-83.

18. Abe T, Hachiro Y, Ebisawa Y, et al. Efficacy and safety of oral lubiprostone in the management of chronic constipation. Nippon Daicho Komonbyo Gakkai Zasshi. 2016;69:6-10.

19. Ford AC, Suares NC. Effect of laxatives and pharmacological therapies in chronic idiopathic constipation: systematic review and meta-analysis. Gut. 2011;60:209-18.

Publisher's Note Springer Nature remains neutral with regard to jurisdictional claims in published maps and institutional affiliations. 